\title{
PERFORMANCE OF THE BASIC FUNCTIONAL ELEMENTS OF HOSPITAL BUILDINGS
}

\author{
*Sara Gamal Abo El-khair, Yasser Mohamed Mansour and Shaymaa Mohamed Kamel \\ Department of Architecture, Faculty of Engineering, Ain Shams University, Cairo, Egypt \\ *Corresponding author E-mail: sara.gamal@eng.asu.edu.eg
}

\begin{abstract}
"A functional design can promote skill, economy, conveniences, and comforts; a nonfunctional design can impede activities of all types, detract from quality of care, and raise costs to intolerable levels." ... [1]

The built environment of hospitals and health care buildings plays an important role as it is the main pillar supporting the system of treatment and health care for patients and creating a good work environment for the employees. As the development or expansion of hospitals over the last ten years, there was a need to evaluate the performance of the basic functional elements of existing hospitals, Therefore the aim of this paper is to define the factors affecting the functional performance of the basic elements in hospitals and to identify its impact on users like patients, staff and visitors. Data collected and discussed in this paper were collected using literature reviews of the factors affecting the functional performance of spaces and the study of their design requirements, And then use field visits, site observation and interviews with the users of the place where these tools are a way to apply postoccupancy evaluation of the building to compare the actual performance of spaces with the desired performance and identify deviations and draw attention to the implications of these deviations, The results obtained can be used to change the design process by improving the built environment to support end-users of the spaces to provide an appropriate working environment for the employees and a supportive healing environment for patients' health.
\end{abstract}

Keywords: Hospitals, Built Environment, Evaluation, Basic Functional Elements, Factors affecting performance.

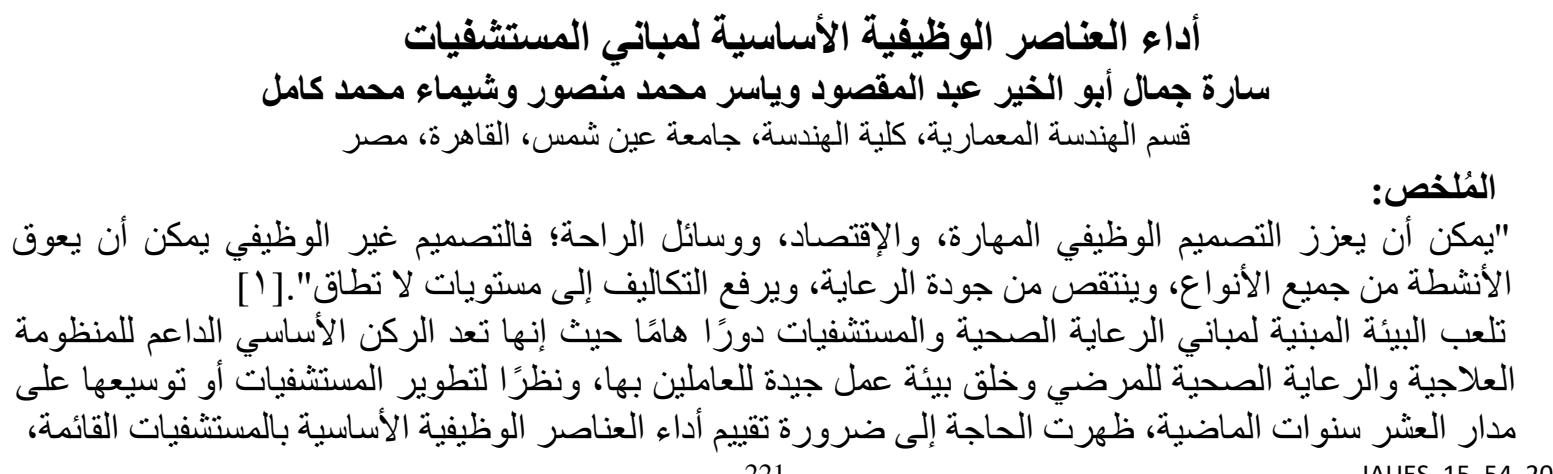


ولذلك الهرف من هذه الورقة هو تعريف العو امل المؤثرة في الأداء الوظيفي للعناصر الوظيفية الأساسية بالمستشفيات

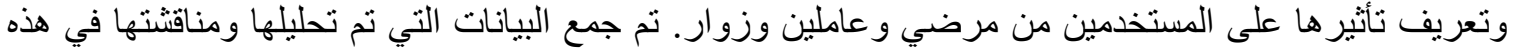

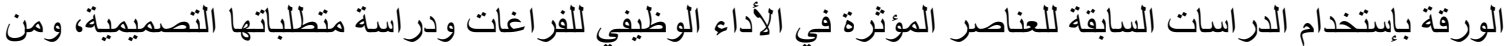

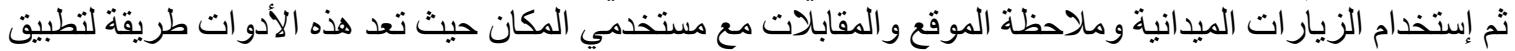

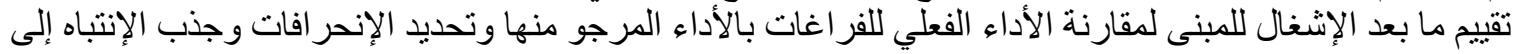

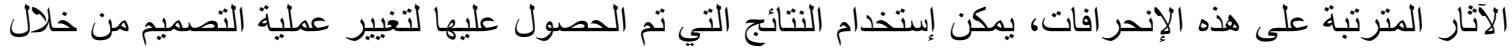
تحسين البيئة المبنية لدعم المستخدمين النهائيين للفر اغات لتوفير بيئة عمل مناسبة للعاملين و بيئة شافية داعمة لصحة الصاتة

المرضي.

الكلمات المفتاحية: المستشفيات، البيئة المبنية، تقييم، العناصر الوظيفية الأسساسية، العوامل المؤثرة في الأداء الوظيفي.

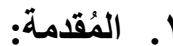

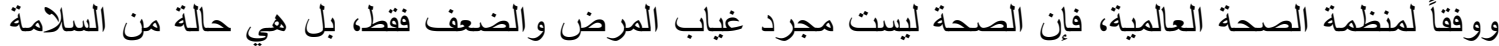

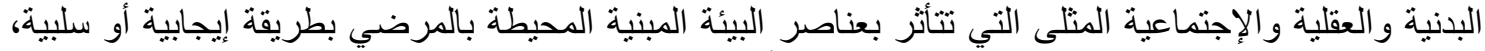

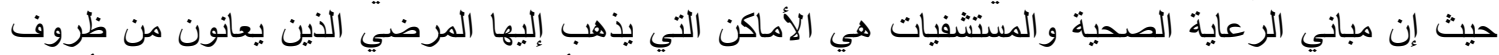

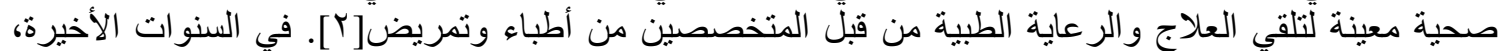

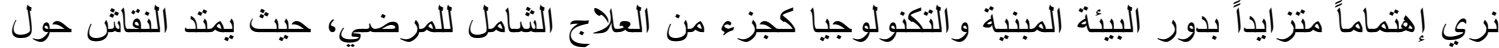

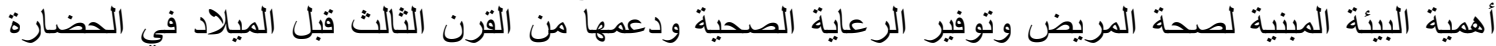

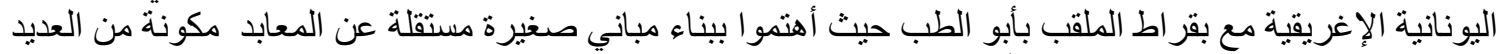

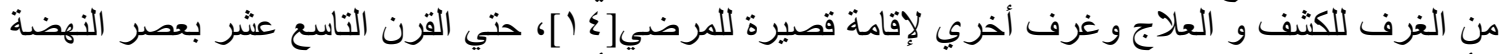

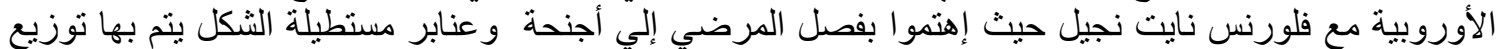

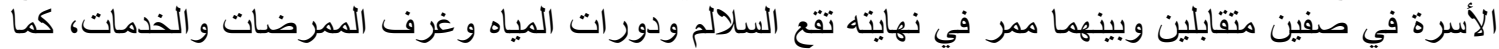

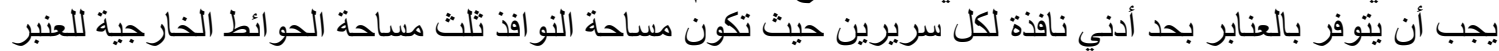

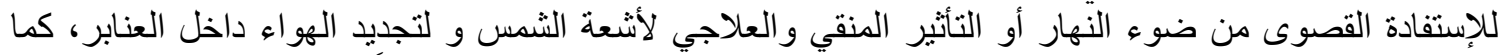

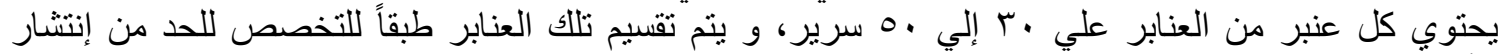

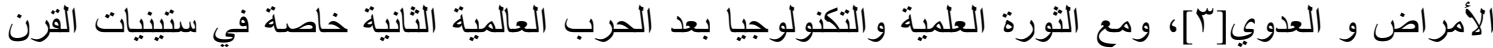

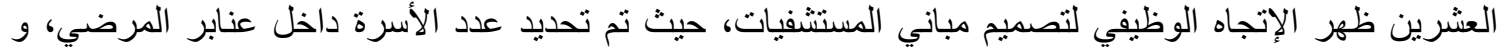

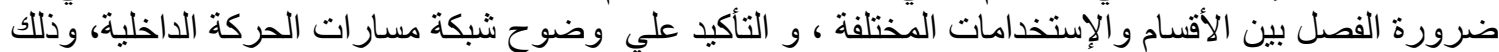

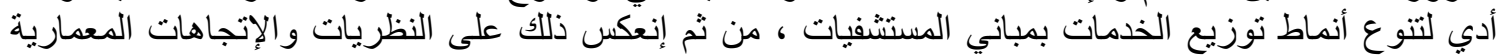

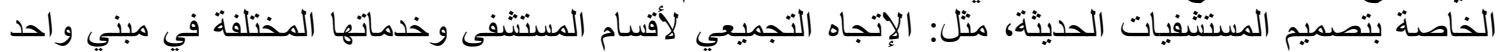

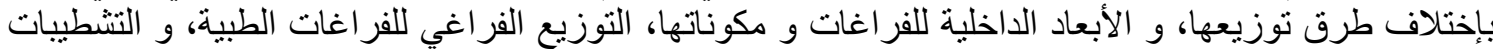

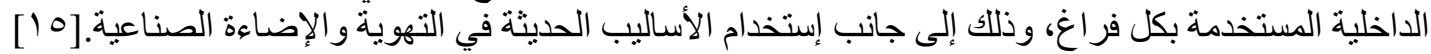

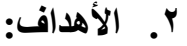

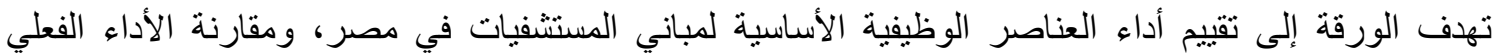

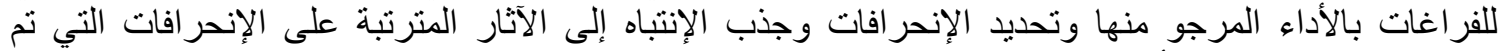

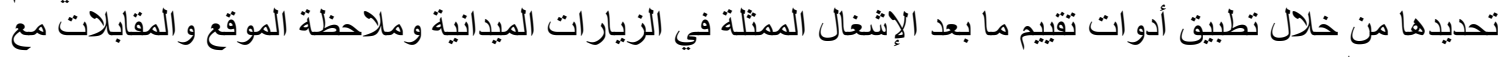
مستخدمي المكان.

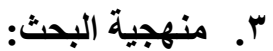

تتألف هذه الورقة من جزأين: الجزء البهة الأول يتضمن ملخص حول دور البيئة المبنية في المستشفيات والعناصر

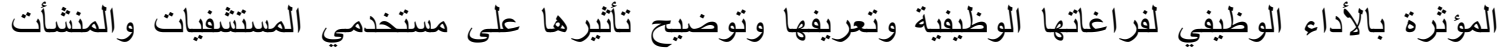

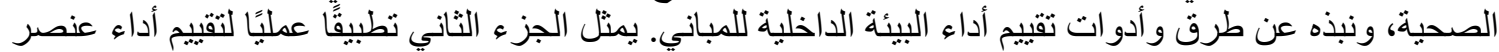

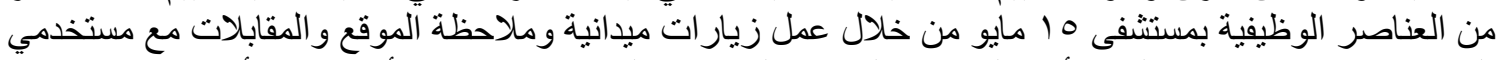

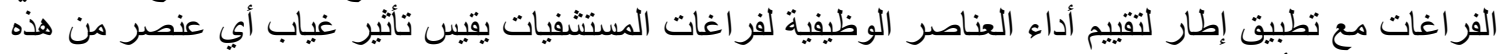
العناصر على الأداء الوظيفي للفر اغات. 
ع. دور البيئة المبنية في المستشفيات:

تمثل البيئة المبنية في الّباني المينية الصحية والمستشفيات بجميع أقسامها الركن الأساسي الداعم للمنظومة العلاجية

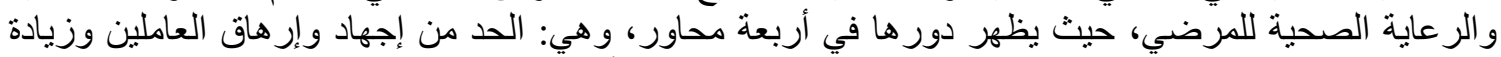

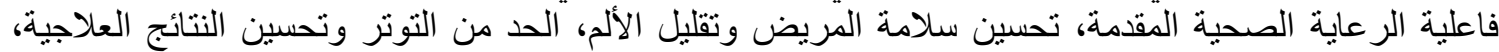

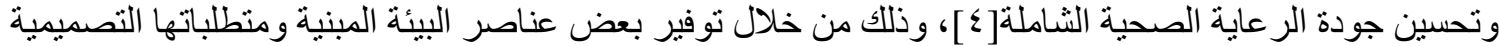

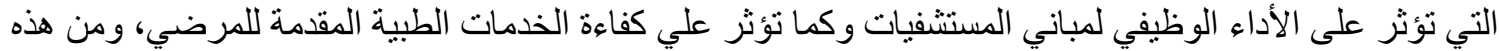

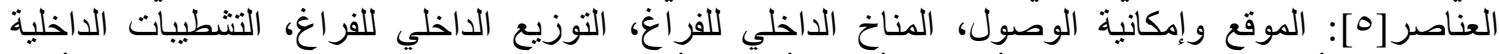

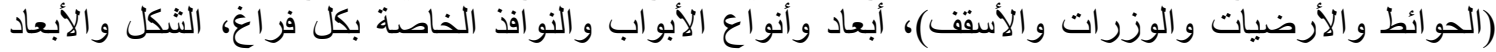
الداخلية (طول، عرض، إرتفاع) ومساحة الفراغ، المكونات والفرش الفران الداخلي، العلاقات الوظيفية الداخلية لكل قسم.

•. تعريف العناصر المؤثرة في الأداء الوظيفي للفراغات وتأثثير ها على المستخدمين:

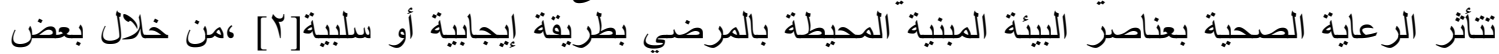

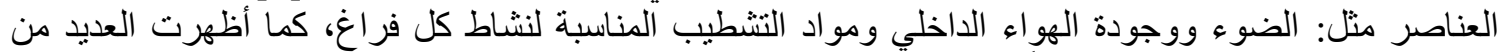

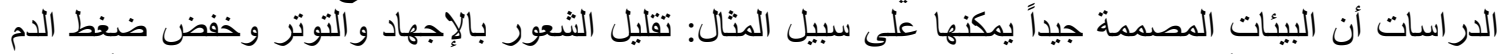

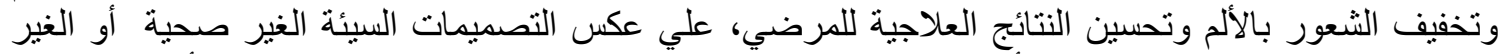

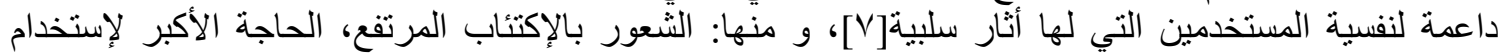

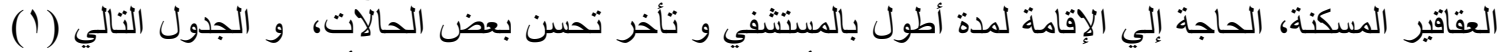

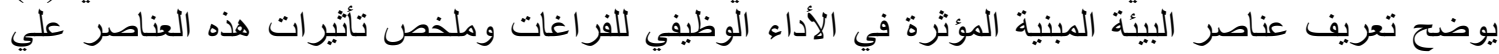

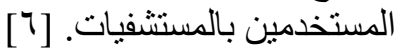

جدول( ' ): تعريف العناصر المؤثرة في الأداء الوظيفي للفر اغات وتأثير ها على المستخدمين

المصدر: الباحث، , DJM V. D. Voordt., Architecture in Use, Architectural press Elsevier, published 2005

\begin{tabular}{|c|c|c|c|c|}
\hline الزائرين & العاملين & المرضي & التأثير & العنصر \\
\hline & & & \multicolumn{2}{|c|}{ 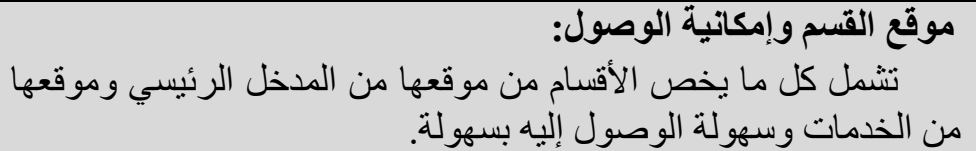 } \\
\hline$\bullet$ & & $\bullet$ & الوصول إلى القّم المطلوب مبانشرين الطريق وسهولة & القرب من المدخل \\
\hline$\bullet$ & • & $\bullet$ & في السير لمسافات طويلة. الجهد على العاملين بالمستشفى & القرب من الخدمات \\
\hline \multirow[t]{5}{*}{ • } & & $\bullet$ & إلى الوجهة المطلوبة. على إيجاد الطريق وسهولة الوصول & وجود علامات \\
\hline & & & \multicolumn{2}{|c|}{ 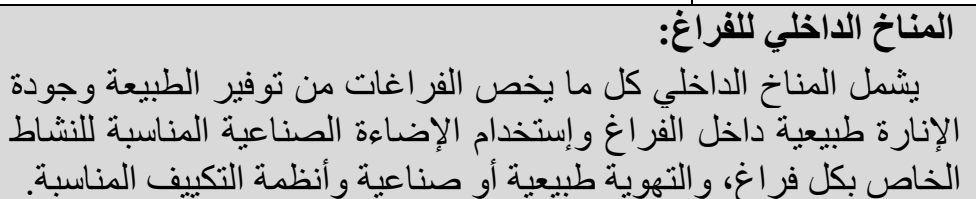 } \\
\hline & & $\bullet$ & 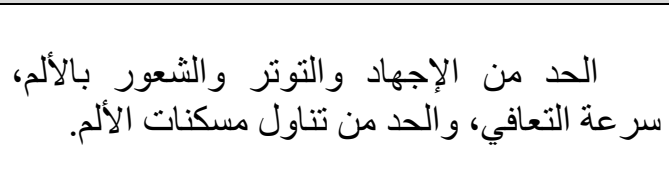 & توفير الطبيعة (منظر طبية) والمناخ \\
\hline & & $\bullet$ & للمرضي و الحد من شعور هم بالإكتئاب. & \\
\hline & 0 & & 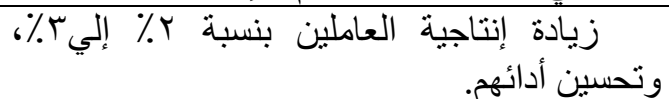 & \\
\hline
\end{tabular}




\begin{tabular}{|c|c|c|c|c|}
\hline$\bullet$ & $\bullet$ & $\bullet$ & شعور أفضل بالوقت والطقس و الموقع. & روئية الضوء \\
\hline \multirow[t]{2}{*}{ • } & $\bullet$ & $\bullet$ & 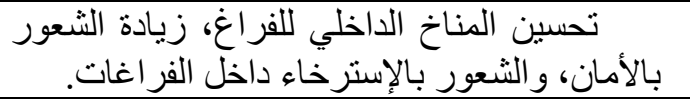 & \multirow{2}{*}{ الصناعية المناسبة } \\
\hline & - & & زيادة إنتاجية العاملين. & \\
\hline • & $\bullet$ & $\bullet$ & 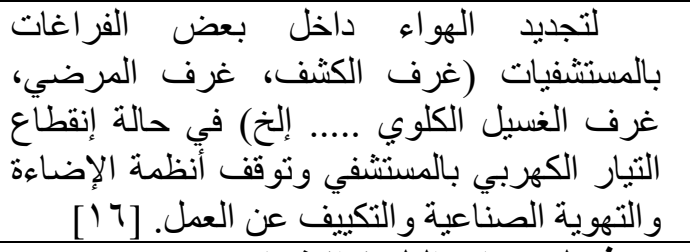 & التهوية الطبيعية \\
\hline \multirow[t]{8}{*}{$\bullet$} & $\bullet$ & $\bullet$ & 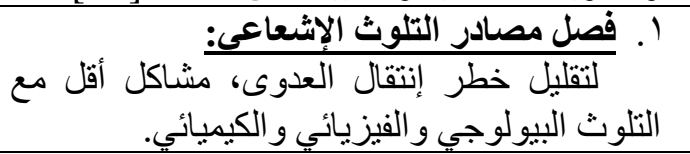 & \\
\hline & $\bullet$ & $\bullet$ & 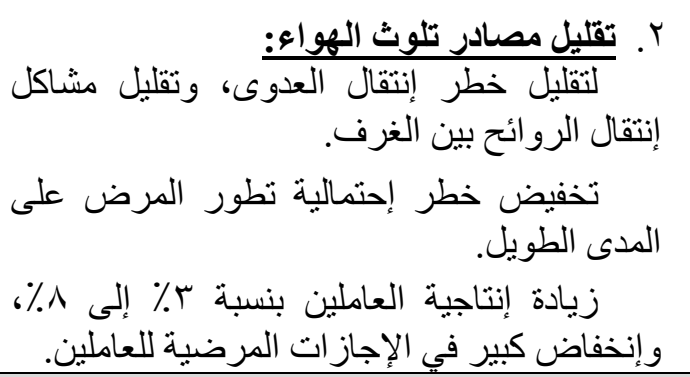 & وأنظمة تكييفة الصناعية \\
\hline & & & 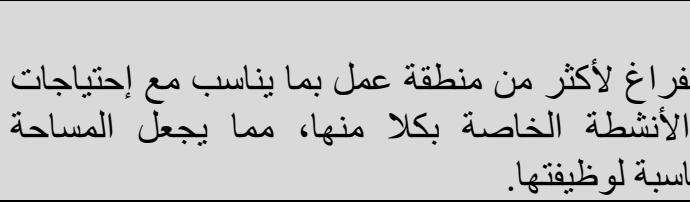 & 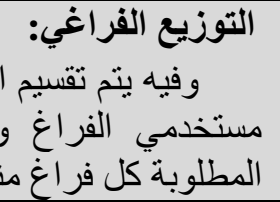 \\
\hline & $\bullet$ & $\bullet$ & 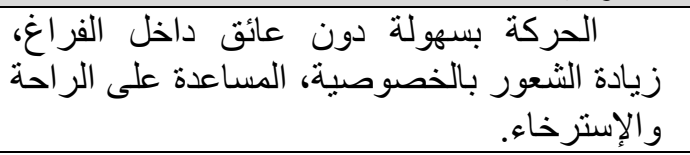 & \multirow{2}{*}{ تحديد مناطق العمل } \\
\hline & $\bullet$ & & زيادة إنتاجية العاملين. & \\
\hline & & $\bullet$ & 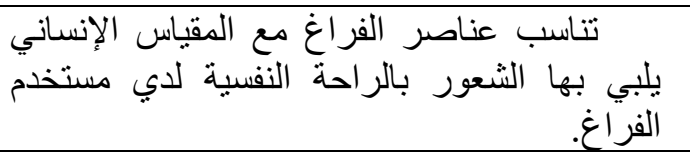 & المقياس الشخصي \\
\hline & & $\bullet$ & 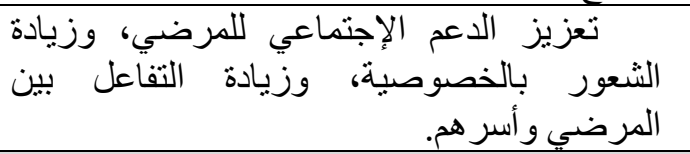 & $\begin{array}{l}\text { للزائرين وصاطق جلوست } \\
\text { إنتظار }\end{array}$ \\
\hline & & & \multicolumn{2}{|c|}{ 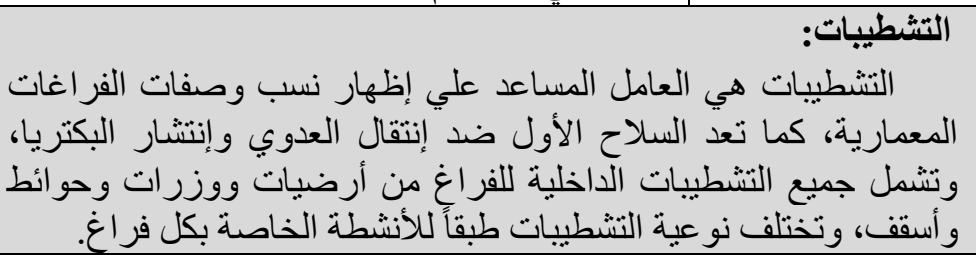 } \\
\hline • & $\bullet$ & $\bullet$ & من سقوط المرضي. أفضل بالتوازن، حركة أكثر أمانًا، الحد & وأرضيات مسطة زلقة \\
\hline - & $\bullet$ & $\bullet$ & لتقليل خطر إنتقال العدوى. & إستخدام مواد مانعة النمو البكريات \\
\hline
\end{tabular}




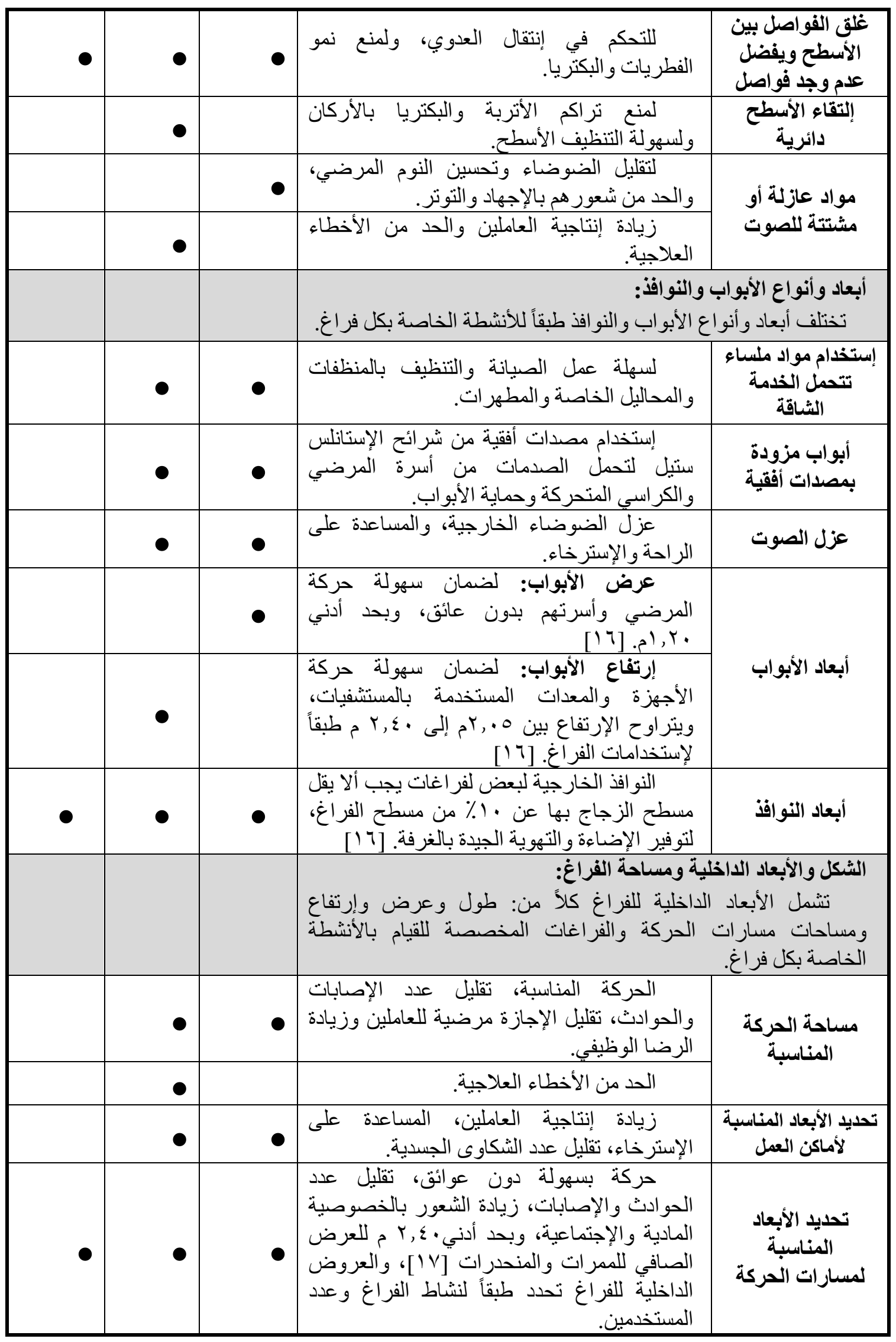




\begin{tabular}{|c|c|c|c|c|}
\hline & $\bullet$ & & العلاجية. زيادة إنتاجية العاملين والحد من الأخطاء & ذاتميم غرف التصميمية \\
\hline & & & \multicolumn{2}{|c|}{ 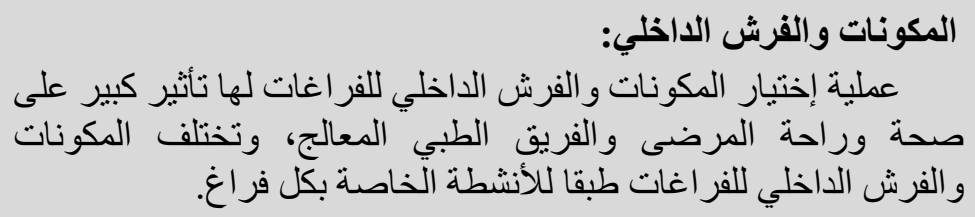 } \\
\hline$\bullet$ & $\bullet$ & - & 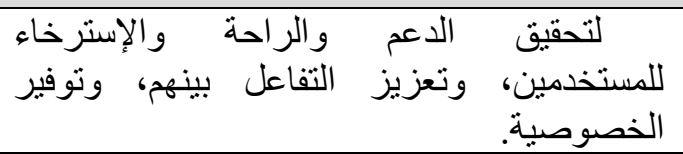 & \multirow{2}{*}{ المناسب للمساحة } \\
\hline \multirow[t]{5}{*}{$\bullet$} & • & $\bullet$ & تقليل عدد الإصـابات و الحو ادث. & \\
\hline & $\bullet$ & & 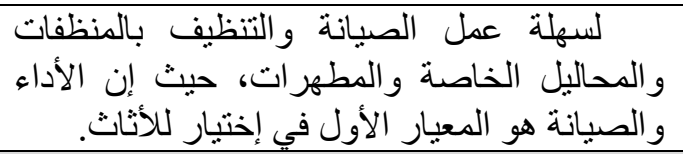 & مواد تتخمل الخدام أثاث من الخدمة \\
\hline & & & 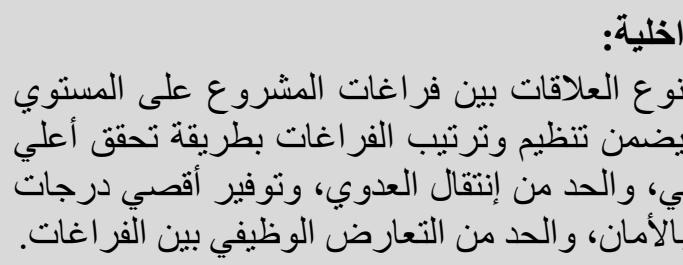 & 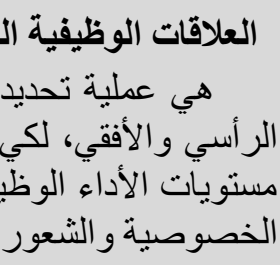 \\
\hline & & $\bullet$ & والحد زن إنتشار العدور بالخصوصية، وزيادة التفاعل، & \multirow{2}{*}{ العلاقات الوظيفية } \\
\hline & $\bullet$ & & زيادة إنتاجية العاملين. & \\
\hline
\end{tabular}

\section{7. طرق تقييم أداء البيئة الداخلية للمباني:}

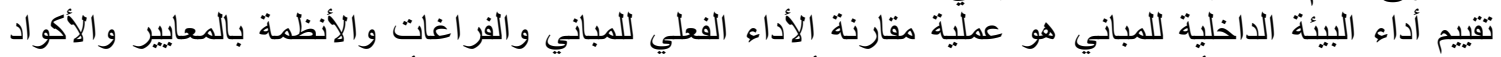

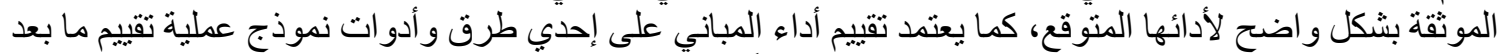

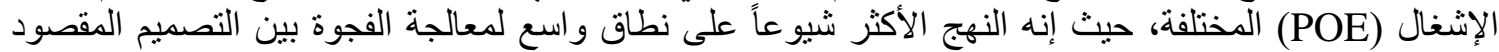

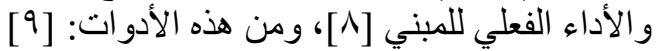

$$
\begin{aligned}
& \text { 1. الملاحظة والتجول بالمبني. } \\
& \text { r. إ. إجر اء المقابلات مع مستخدمي المكان. } \\
& \text { r. عمل الإستبيانات. }
\end{aligned}
$$

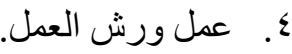

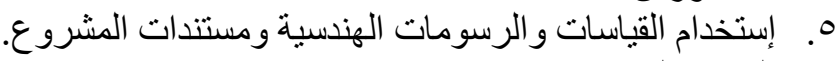

$$
\begin{aligned}
& \text { 7. . الوثائق الفوتو غر افية. }
\end{aligned}
$$

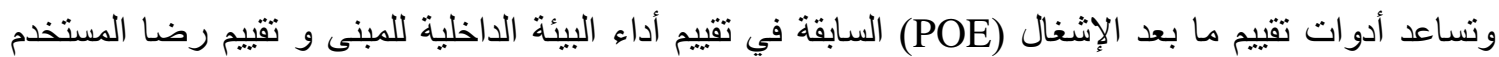

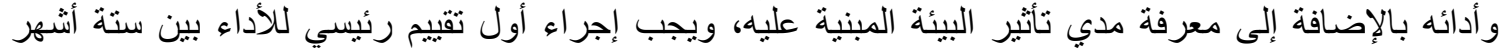

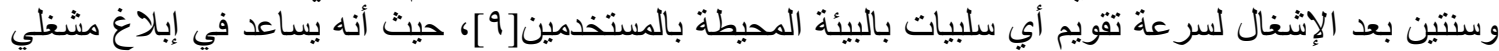
المبني بالمناطق و العناصر التي تحتاج إلى تحسين، وتقديم ملاحظات لمصممي ومشغلي المباني حول المينة الميزات 
التصميمية للمبني الحالي وإستر اتيجيات التشغيل التي تؤدي إلى تحسين تصميمات المباني المستقبلية المماثلة حتي

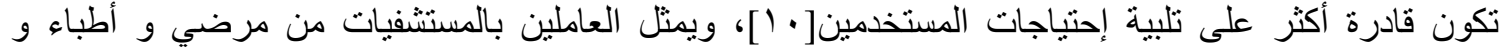
تمريض المصدر الرئيسي للمعلومات من خلال إجر اء المقابلات أو الإستبيانات بمباني المستشفيات.

V. المتطلبات التصميمية للعناصر المؤثرة في الأداء الوظيفي لقسم العناية المركزة:

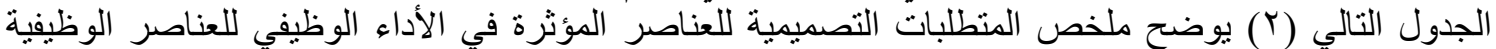
الأساسية بقسم العناية المركزة، وهي مناطق التعامل مع المرضي من عنابر مفتوحة أو الو كبائن أو غرف لأف فردية. جدول( ؟): جدول توضيحي للمنطلبات التصميمية للعناصر المؤثرة في الأداء الوظيفي بمنطقة المرضي بقسم العناية المركزة المصدر: الباحثث

\begin{tabular}{|c|c|c|c|}
\hline \multicolumn{4}{|c|}{ ة المرضى (عنابر - كبائن - غرف فردية) } \\
\hline 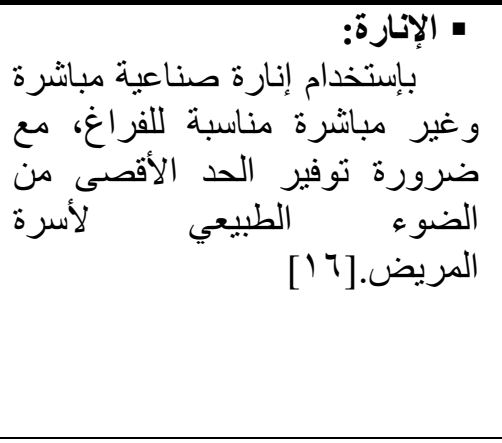 & \multicolumn{2}{|l|}{ 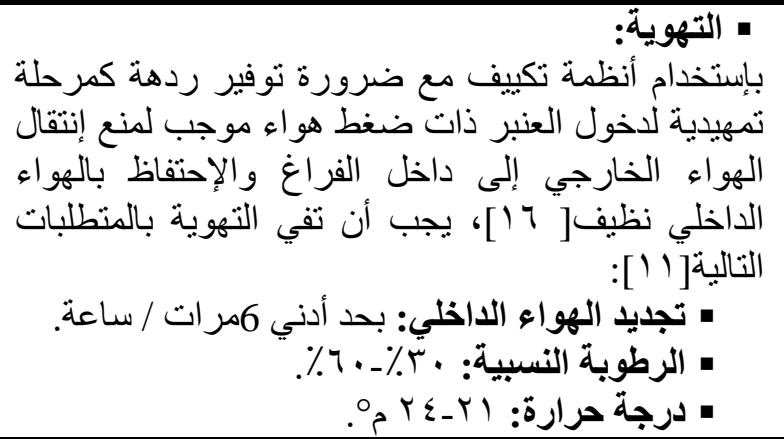 } & \\
\hline شكل( '): التوزيع الفر اغي للعناية المركزة & \multicolumn{2}{|l|}{ 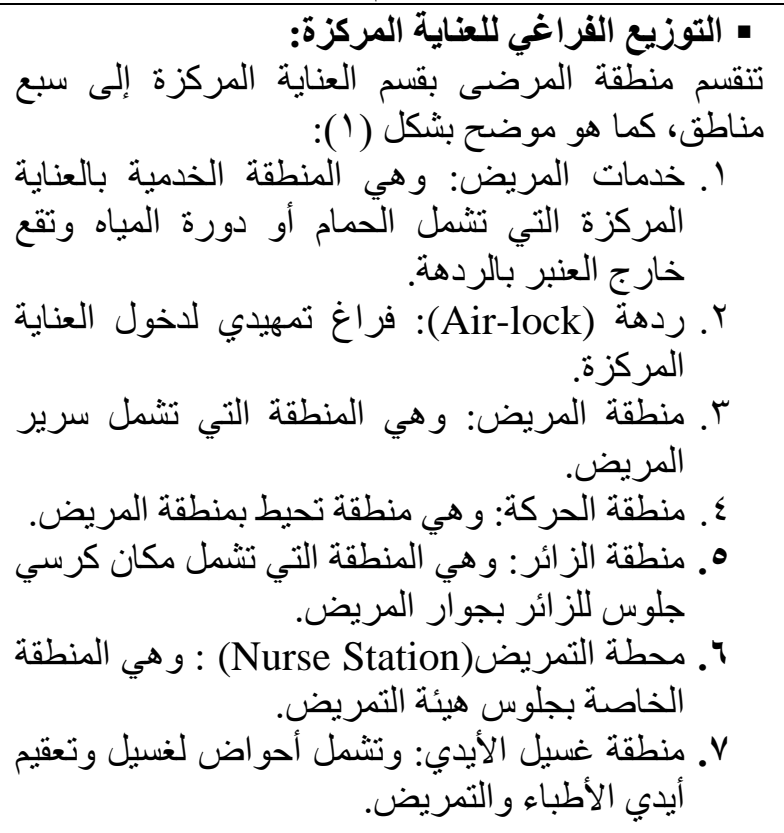 } & \\
\hline \multicolumn{3}{|c|}{ 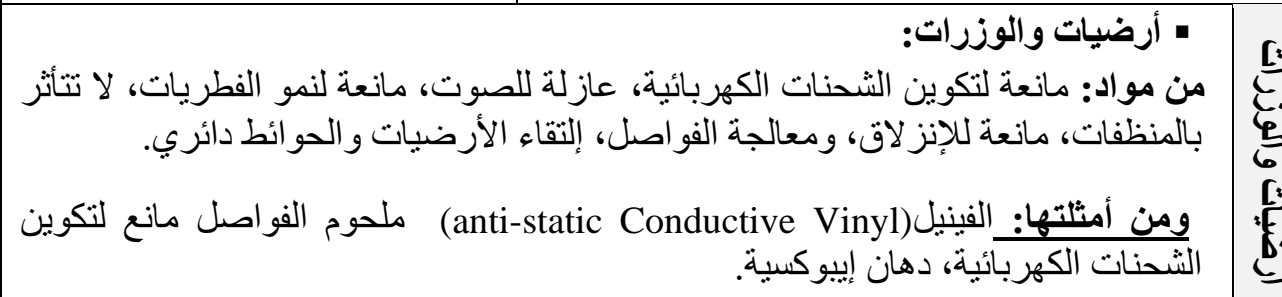 } & \\
\hline
\end{tabular}




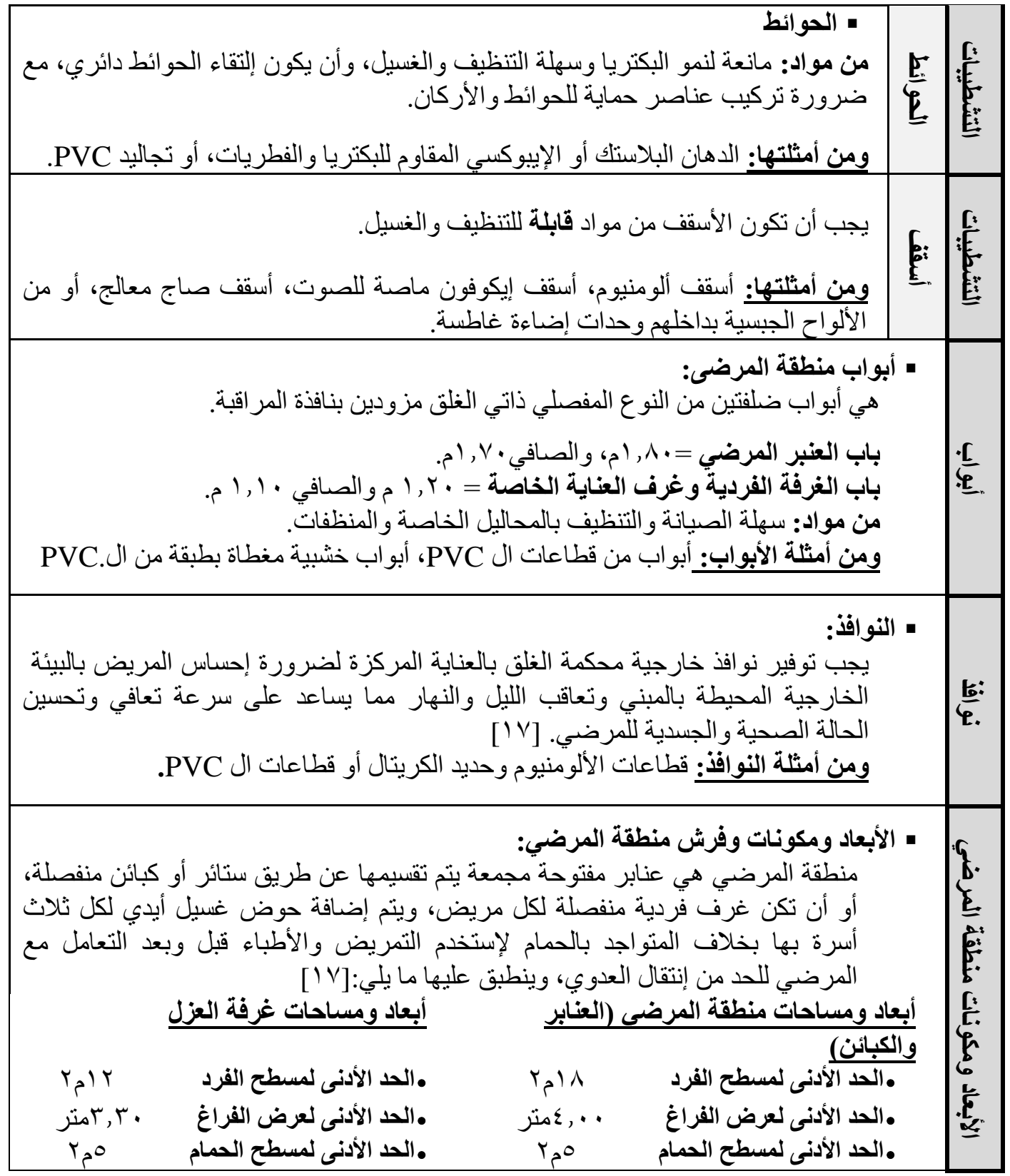

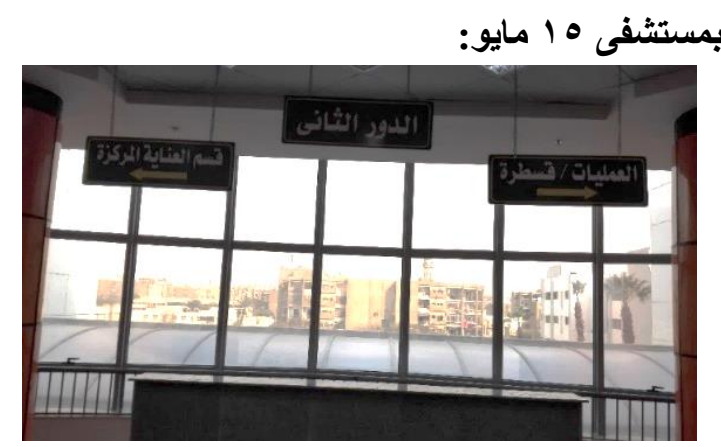

شكل( ץ) : العلامات الإرشادية لقسم العناية المركزة بالدور الثاني المصدر: الباحث
^. تحليل العناصر الوظيفية الأساسية بقسم العناية المركزة بمي • موقع القسم وإمكانية الوصول:

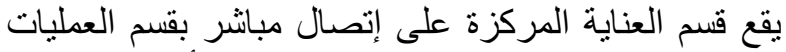

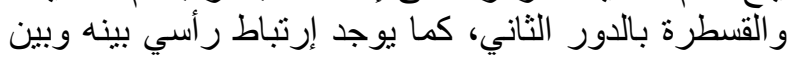

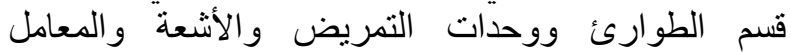

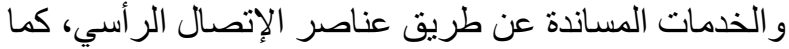

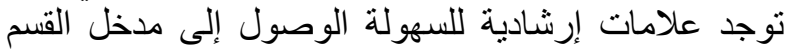

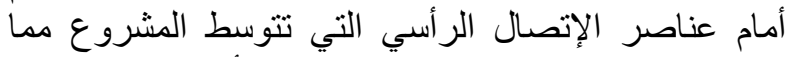

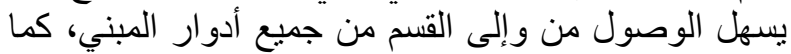
هو موضح بالثكل (r) (ب) 

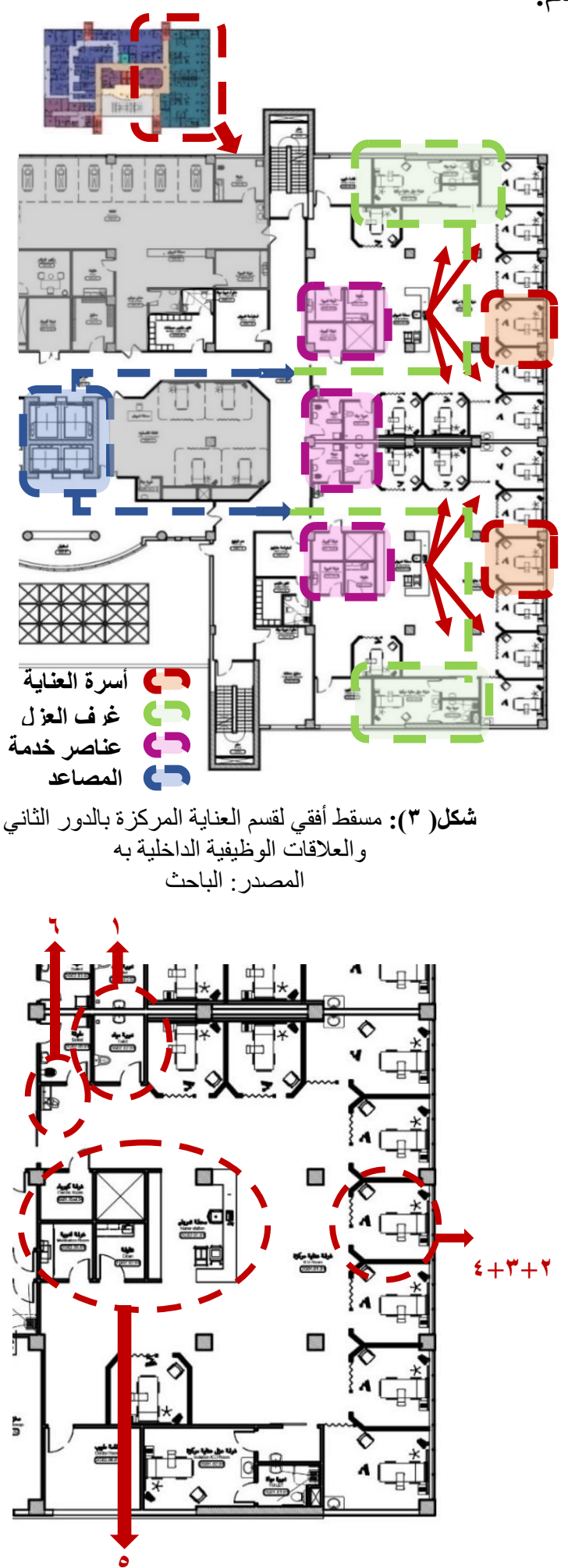

شكل( ؛): التوزيع الفر اغي لصالة العناية المركزة
ـ العناصر الوظيفية والعلاقات الوظيفية الداخلية بالقسم:

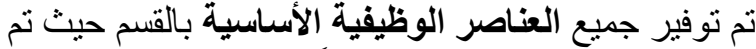

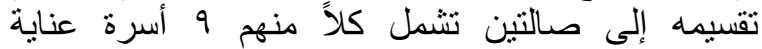

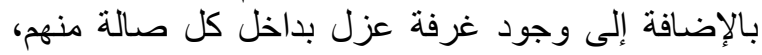

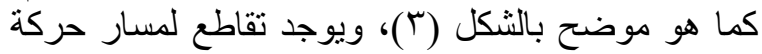

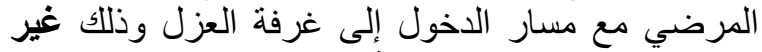

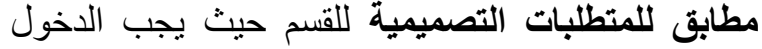

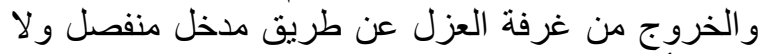

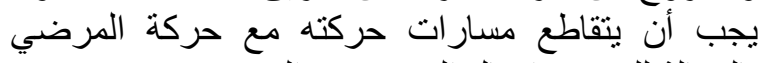

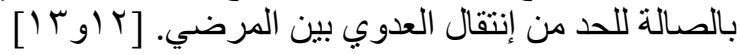

كما تم توفير جميع العناصر الخدمية داخل صالة العناية

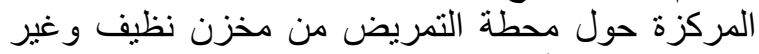
نظيف ومخزن أدوية و غرفة سجلات طبية، حيث تنوسن نظون

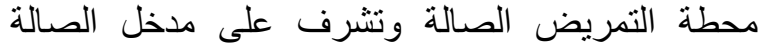

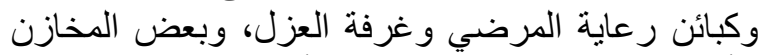

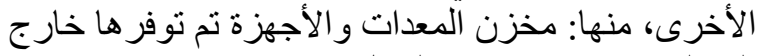

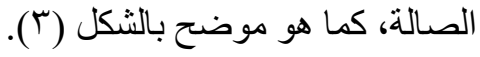

كما تم توفير بعض العناصر الإدارية خارج الصالة،

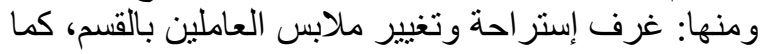

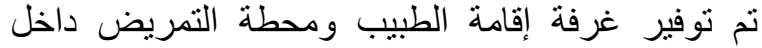

الصالة، كما هو موضح بالشكل (ب) الطنة

$$
\text { أ. صالة العناية المركزة: }
$$

تم توفير التهوية الصناعية من خلال الإن توفير نظام تكييف

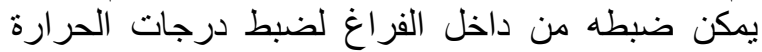

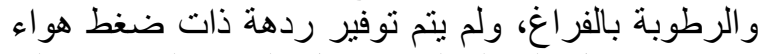

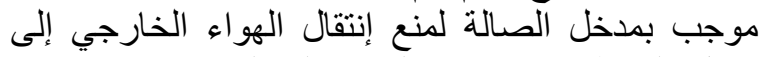

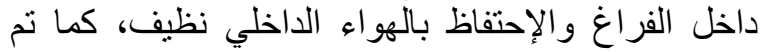
توفير وحدات إنارة مباشرة بسقف الأفراغ الفراغ وغير مباشرة

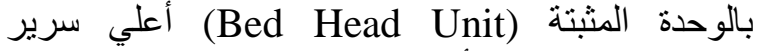
المريض، ولا يوجد أي مصدر لاخول الإنارة الطبيعية للفراغ.

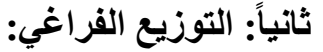

تم تقسيم صالة العناية المركزة إلى ست مناطية الفراغق، كما هو

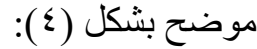

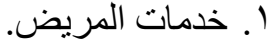

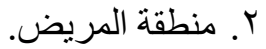

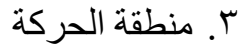
ع. منطقة الز ائرين. منطة المركة 0. محطة التمريض وغرف الزئ خدمية. 7. منطقة غسيل الأبدي، بعيدة عن محطة التمريضة

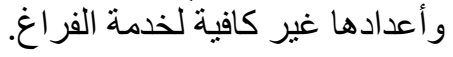


V. ولم يتم توفير ردهة (Air-lock) بمدخل الصالة لمنع إنتقال الهو اء الخارجي إلى داخل الفر اغ و الإحتفاظ بالهو اء الداخلي نظيف.

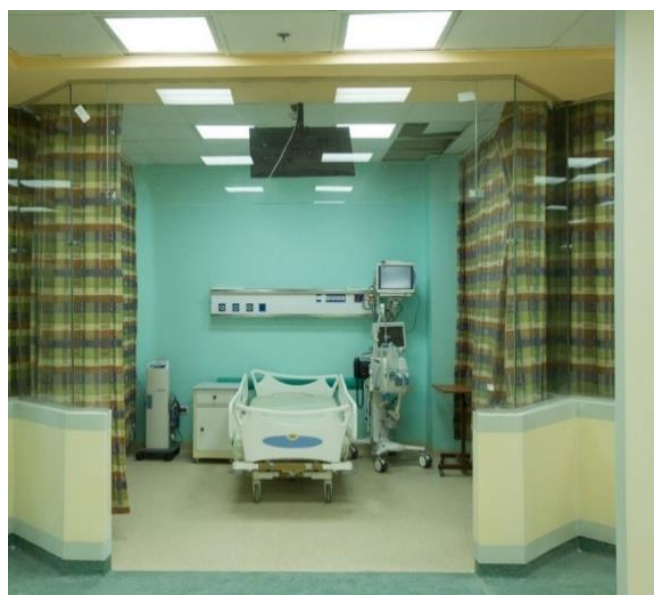

شكل( •): التشطيبات الداخلية بصالة العناية المركزة

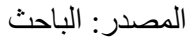

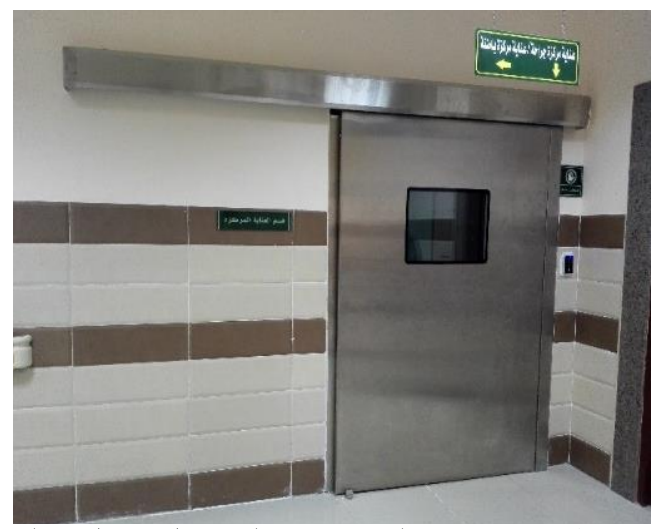

شكل(V)): باب منزلق من الإستانلس ستيل بمدخل صالة العناية المركزة الإنبانة المصدر : الباحث: المنة

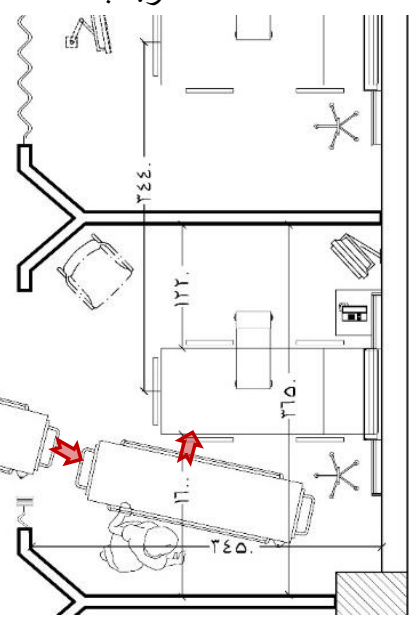

شكل( "): مسقط أفقي يوضح أبعاد ومكونات كبينة العناية

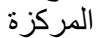
المصدر: الباحث
ثالثاً: التشطيبات:

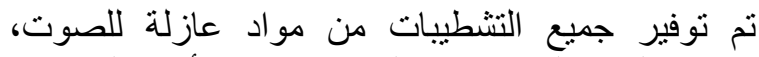

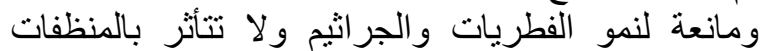

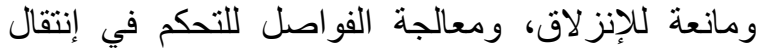

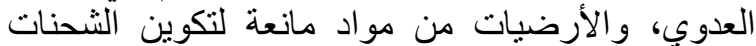
الكهربائية، كما يلي: الإنيات

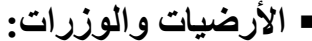

تم إستخدام أرضيات ووزرات من الفينيل ماتوزيل ملحوم الفواصل مانع لتكوين Conductive Vinyl) الشحنات الكهربائية، كما هو موضح بالثكل (0).

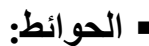

كبائن المرضي: نم إستخدام دهانات مقاومة لنمو البكتريا

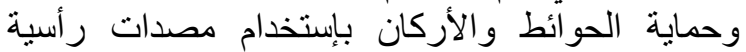
و أفقية من اللدائن، كما هو موضح بالطية بالثكل (0).

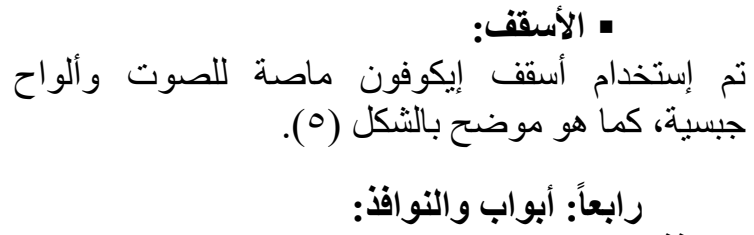

النوافذ: لا توجد نوافواف خارجية لتوفير الإضواءوة الطبيعية

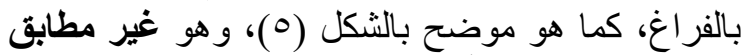
للمنطلبات التصميمية حيث تساعد الإضاءة الطبيعية في

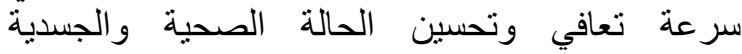

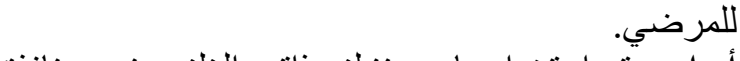
أبواب: تم إستخدام باب منزلق ذاتي الغلق مزود بنافذة

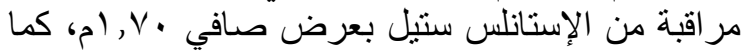

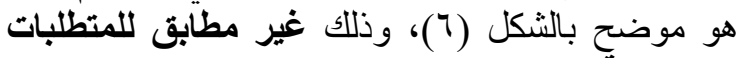
التصميمية.

\section{خامساً: أبعاد ومكونات وفرش:}

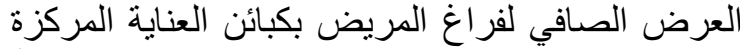

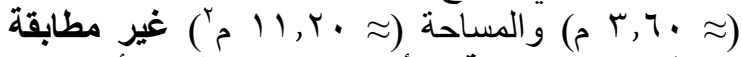

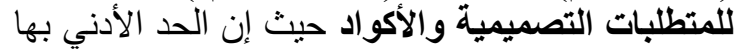

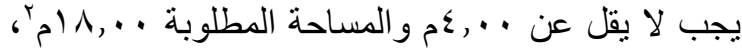

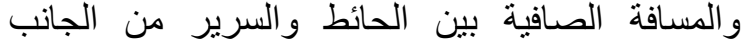

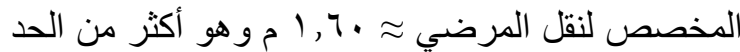
الأدني للمسافة الخاصة بنقل المرضي وهي كما هو موضح بالثكل (V) 
ب. غرفة عزل العناية المركزة:

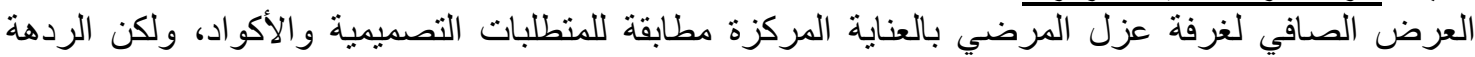

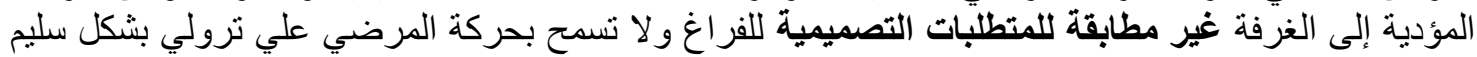

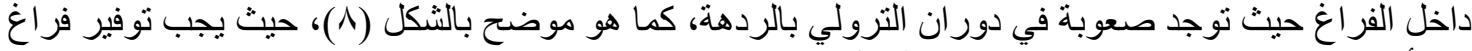

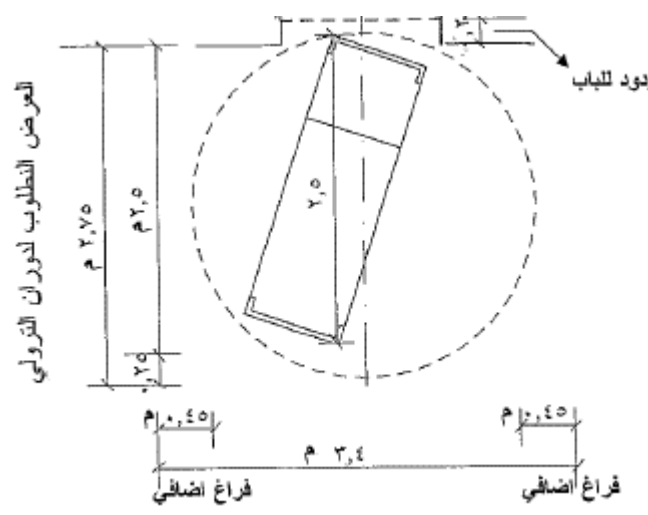

شكل( 9): العرض المطلوب لدوران ترولي المبي

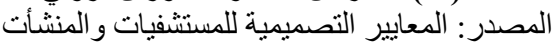

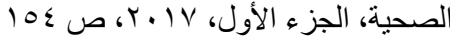

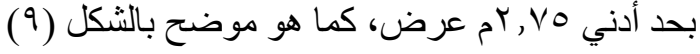

\section{• إطار تقييم أداء العناصر الوظيفية الأساسية بقسم العناية المركزة:}

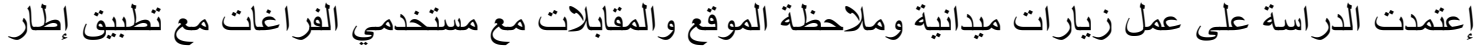

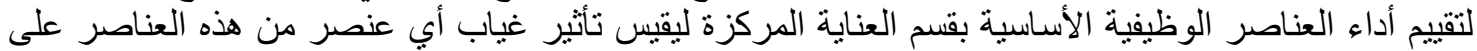

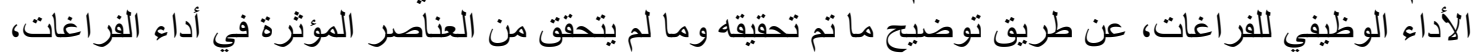

كما هو موضح بالجدول (r).

جدول( ب): إطار تقييم أداء العناصر الوظيفية الأساسية بقسم العناية المركزة

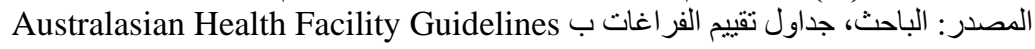

\begin{tabular}{|c|c|c|c|c|}
\hline$\underline{\underline{k}}$ & $\frac{e_{i}^{2}}{2}$ & $e_{i}$ & إطار تقييم أداء العناصر الوظيفية بالعناية المركزة & \\
\hline \multirow[t]{2}{*}{$\% 9$. } & $\begin{array}{l}\square \\
\square \\
\square\end{array}$ & $\boldsymbol{\square}$ & 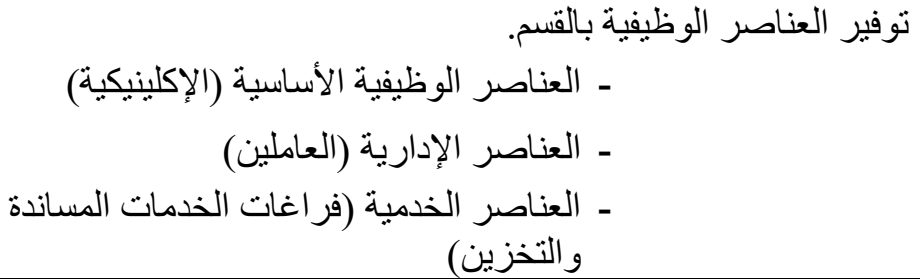 & \multirow[t]{2}{*}{$\begin{array}{l}\text { E. } \\
\text { E. } \\
\text { E. } \\
\text { E. } \\
\text { E. } \\
\text { E. }\end{array}$} \\
\hline & $\mathbf{\square}$ & $\square$ & مر اعاة العلاقات الوظيفية الداخلية بين العناصر الوظيفية للقسم. & \\
\hline \multirow{4}{*}{$\%$} & $\square$ & $\mathbf{\square}$ & درجات الحرارة و الرطوبة مناسبة لنشاط الفراغ & \multirow{4}{*}{ 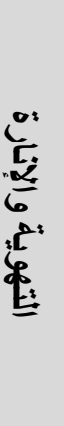 } \\
\hline & $\square$ & U & مكونات الفراغ الإناءة ملائم للرؤية و التو اصل مع الوسط المحيط ووضوح & \\
\hline & $\mathbf{\square}$ & $\square$ & 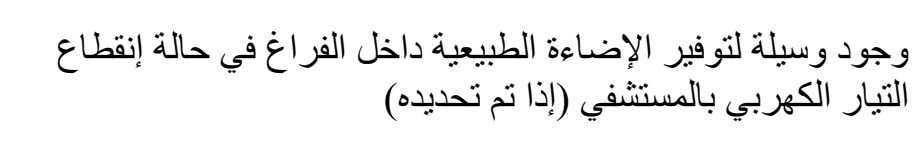 & \\
\hline & $\square$ & $\boldsymbol{\square}$ & 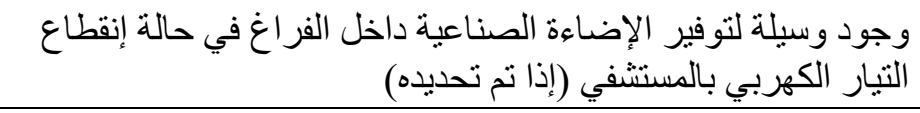 & \\
\hline
\end{tabular}




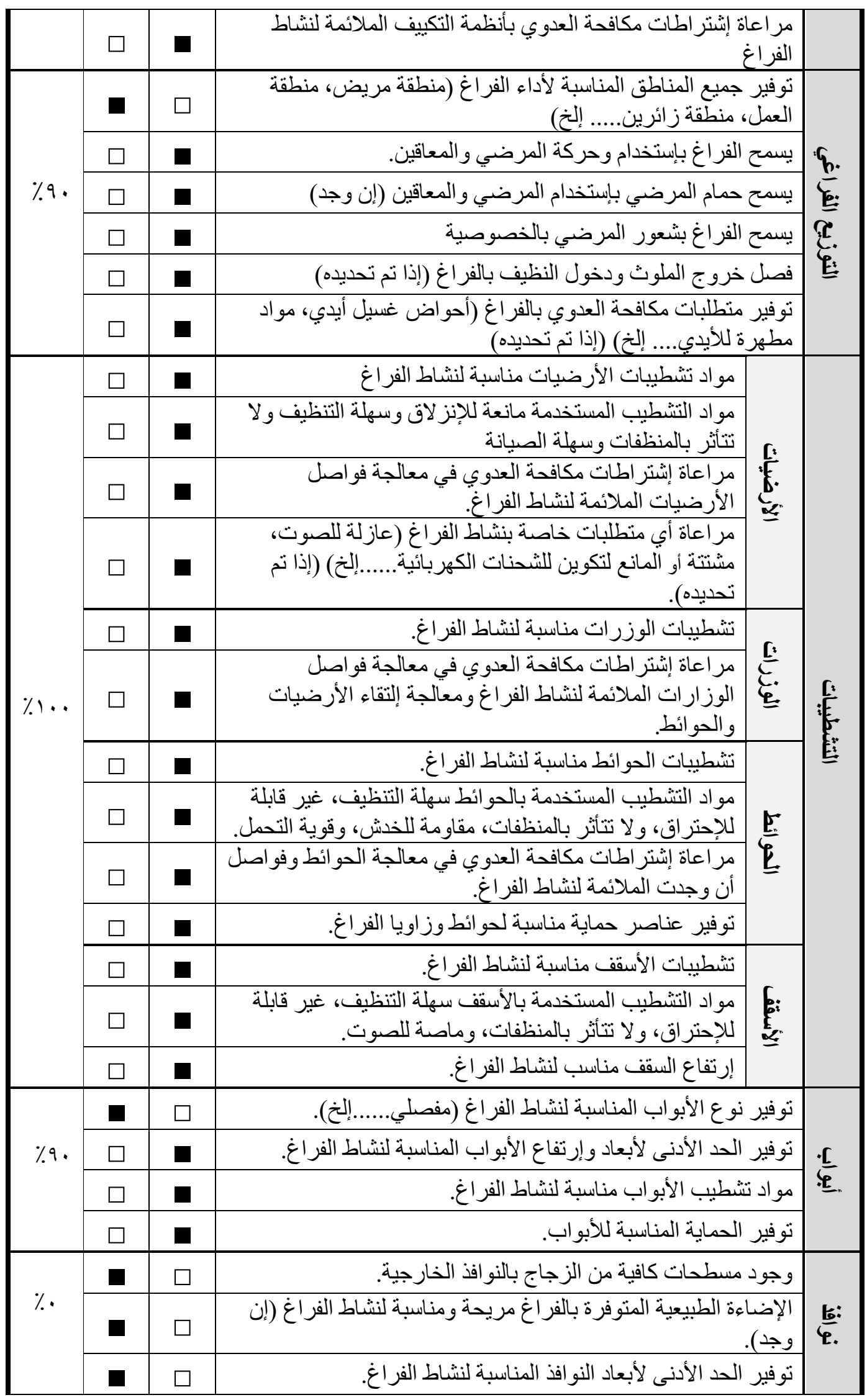




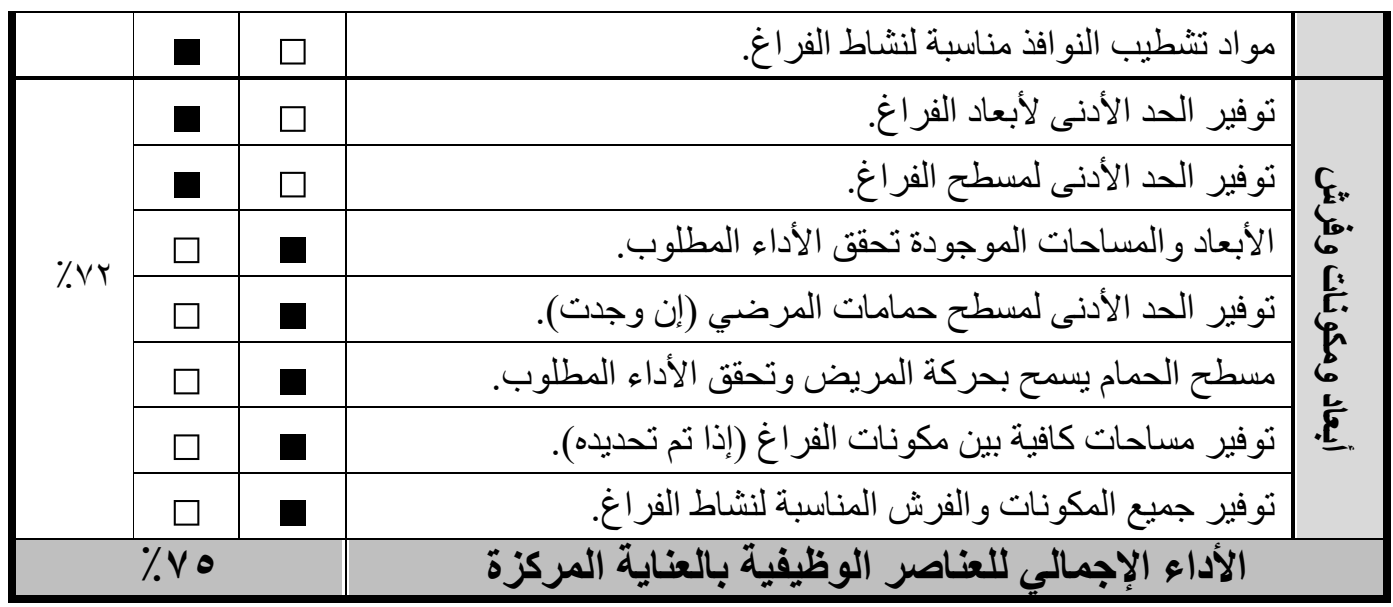

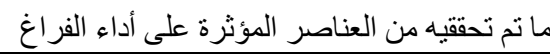
تم حساب نسبة أداء كل عنصر =

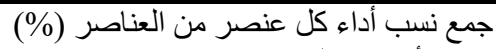

تم حساب نسبة الأداء

ملحوظة: إجمالي عدد العناصر

الإجمالي للعناصر الوظيفية

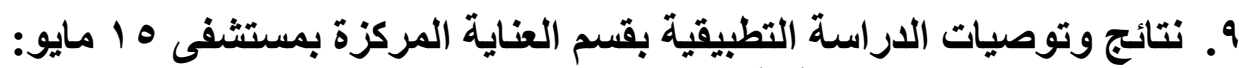

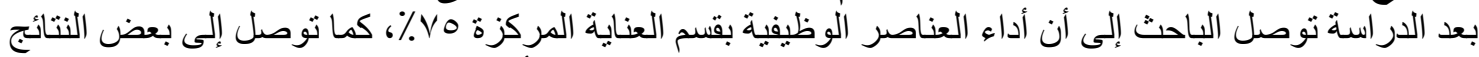
و التوصيات الهامة التي يجب مر اعاتها عند تصميم العناصر الوظيفية الواءية الأساسية بقسم العناية المركزة، تتمثل فيما

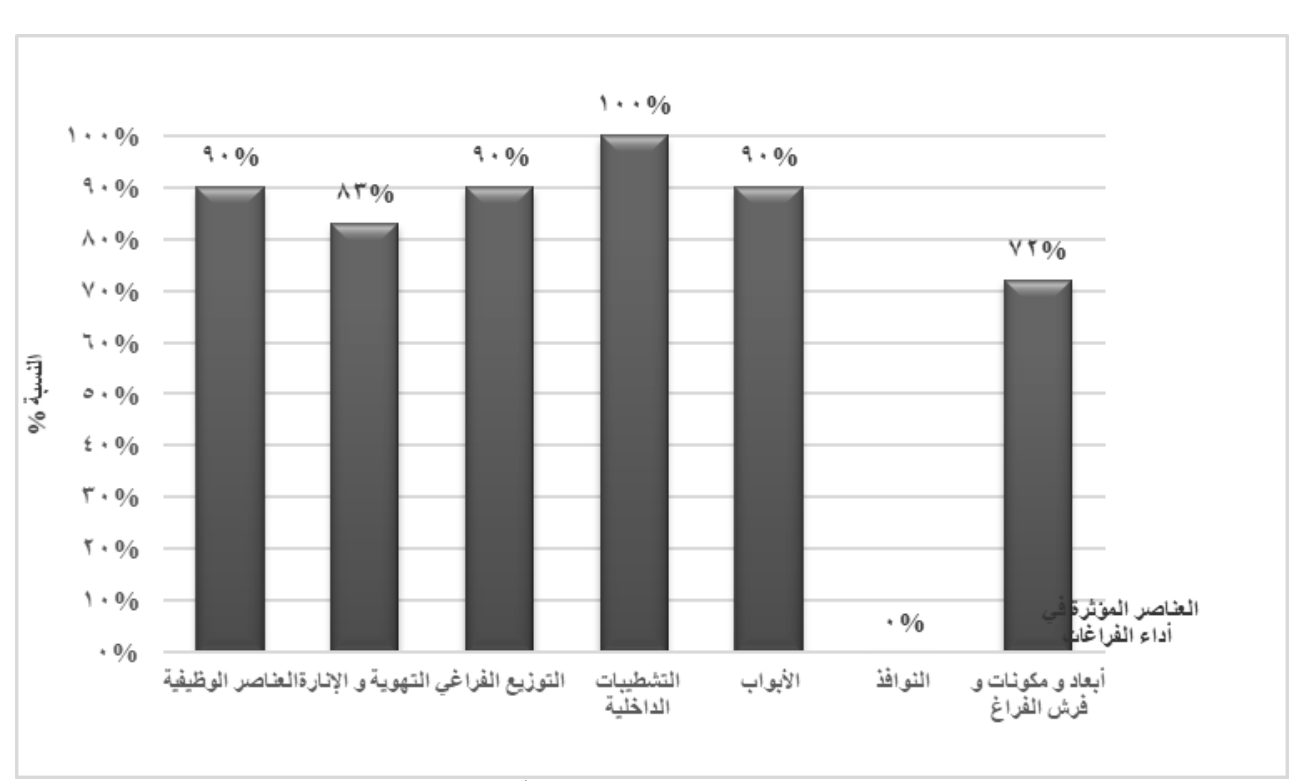

شكل( · (1): رسم بياني يوضح مدي تحقيق العناصر المؤثرة في أداء كبائن وغرف العزل بقسم العناية المركزة المصدر: الباحث

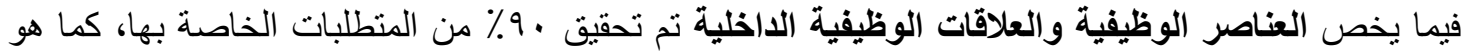

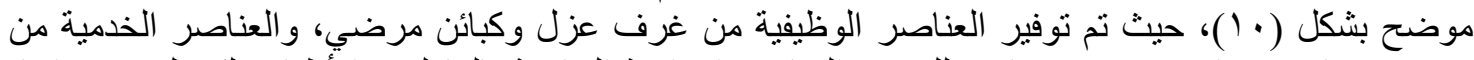

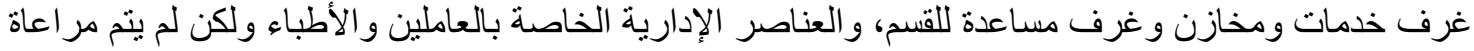

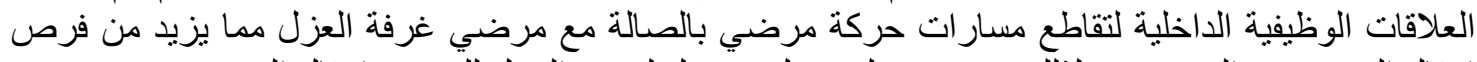
إنتقال العدوي بين المرضي، ولذلك نوصي بعمل مدخل منفصل لغرف العزل التهار للحد من إنتقال العدوي. 


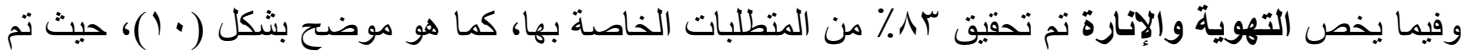

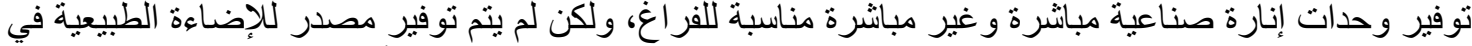

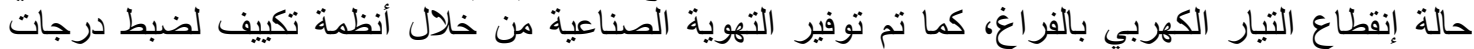

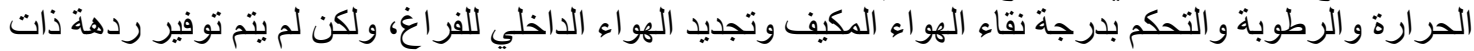

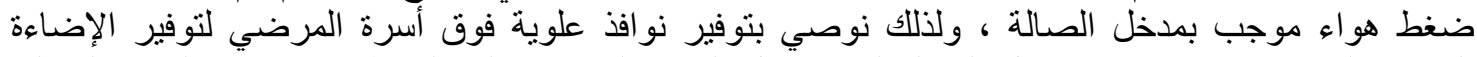

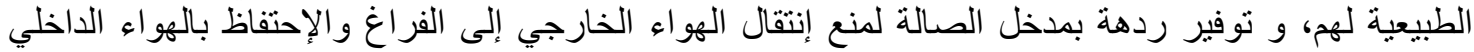

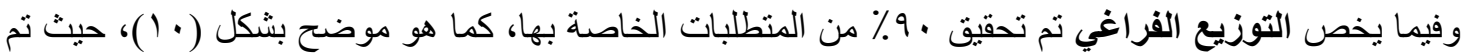

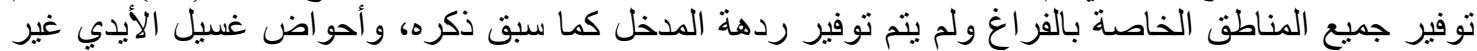

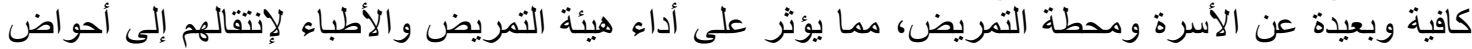

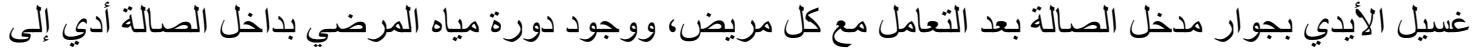

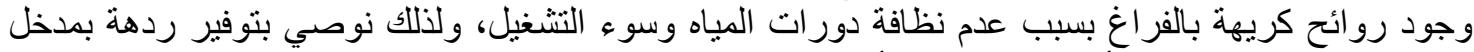

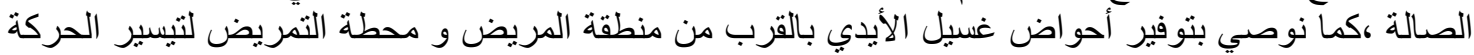

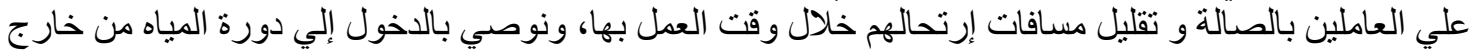
فر اغ الصالة للاحتفاظ بالهو اء الداخلي نظيف.

وفيما يخص التشطيبات الداخلية تم تحقيق . ( ٪ من المتطلبات الخاصة بها، كما هو موضح بشكل (· • ()، تم

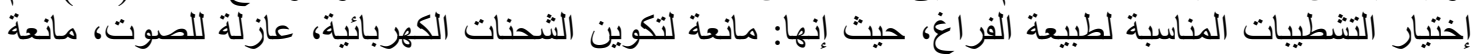

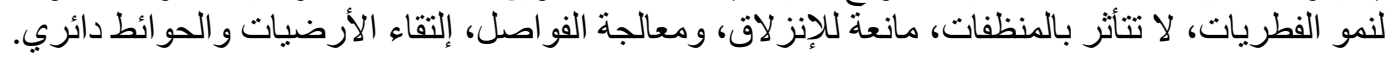

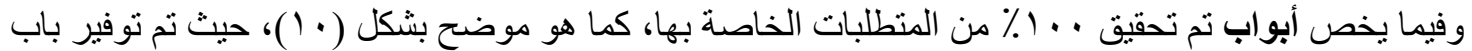

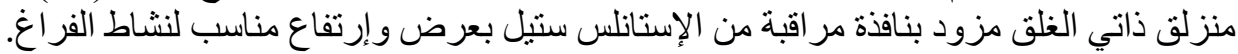

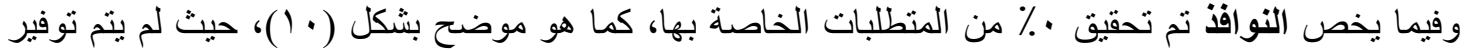

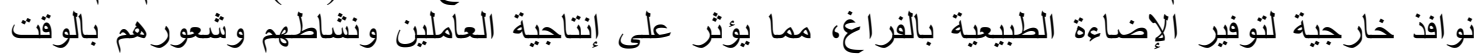

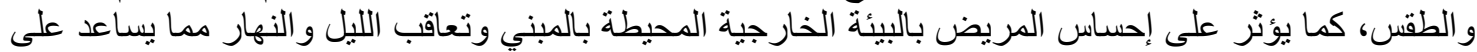

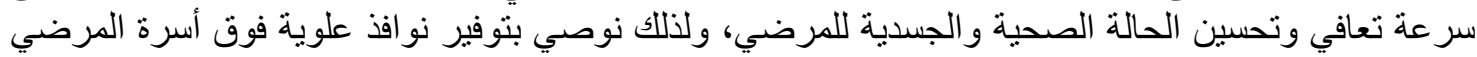
لتوفير الإضـاءة الطبيعية لهم.

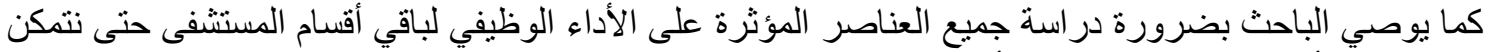

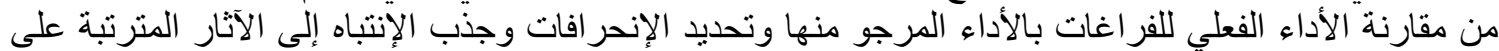

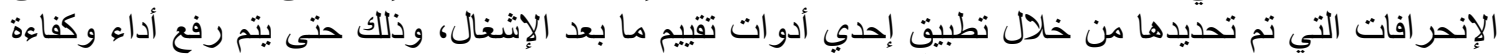

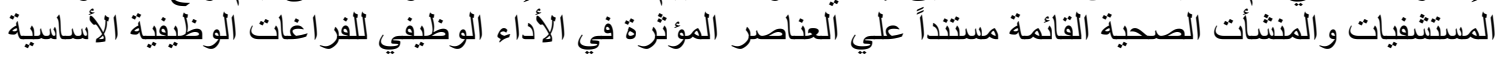

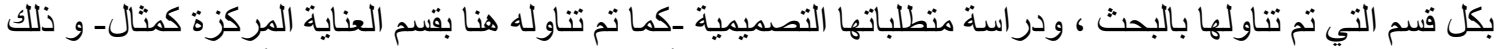

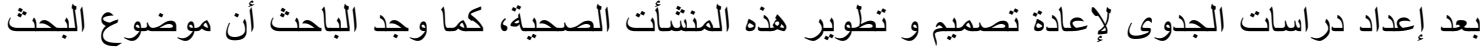

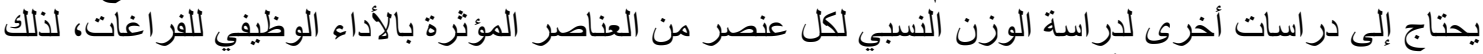
توصى الدارسة بمزيد من الأبحاث في هذا الإنجات الإنجاه.

\section{المراجع

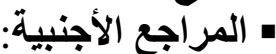

1. Hardy B. Owen \& Lammers P. Lawrence (1977). Hospitals, the Planning and Design Process. Second Edition. USA: Aspen Systems Corporation.

2. WHO. (1948, April 7). Official Records of the World Health Organization. Volume2, p. 100.

3. Nightinagle, F. (1863). Notes on Hospitals. Third Edition, London, USA: Longman. 
4. Ulrich, Roger S. \& Zimring, Craig (2004). The Role of the Physical Environment in the Hospital of the 21st Century: A Once-in-a-Lifetime Opportunity. New York, USA: Center for Health Systems and Design.

5. Ulrich, Roger S. (2000), Effects of Healthcare Environmental Design on Medical Outcomes, New York, International Academy for Design and Health.

6. Voordt, DJM van der \& Wegen, HBR van (2005). Architecture In Use. London, USA: Architectural press Elsevier.

7. Ulrich, Roger S. (2000). Evidence based environmental design for improving medical outcomes, Montreal. Proceedings of the Conference Healing by Design, McGill University Health Centre.

8. Preiser, Wolfgang F. E. \& Vischer, Jacqueline C. (2006). Assessing Building Performance. Oxford, United Kingdom: Elsevier.

9. Preiser, Wolfgang F. E. (1989), Building Evaluation, Second Edition, New York, USA: Springer Science +Business Media.

10. Hay, R. et al. (2017), Building Knowledge: Pathways to Post Occupancy Evaluation, RIBA: University of Reading.

11. ASHRAE (2013). Ventilation of Health Care Facilities, ANSI/ASHRAE/ASHE Standard 170-2013. USA: ASHE publisher.

12. FGI (2014). Guidelines for Design \& Construction of Health Care Facilities. USA: ASHE publisher.

13. HCAMC, U. o. (2016). Australasian Health Facility Guideline (Vol. Part D: Infection Prevention and Control). Australia: the Australasian Health Infrastructure Alliance.

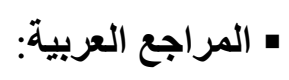

ـ ا ـ السرجاني، ر اغب (9 . . ץ). قصة العلوم الطبية في الحضارة الإسلامية. القاهرة، مصر : مؤسسة أقر اللنشر و التوزيع.

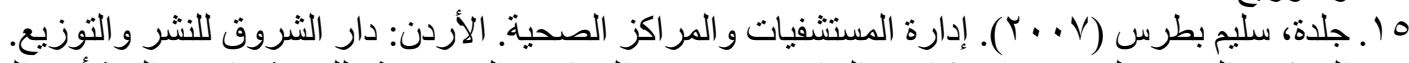
جا المركز القومي لبحوث الإسكان والبناء (2017). المعايير التصميمية للمستشفيات والمنشأت الصنية الصحية المتخصصة. الجزء الثاني. القاهرة: دار الكتب الأبكان المصرية.

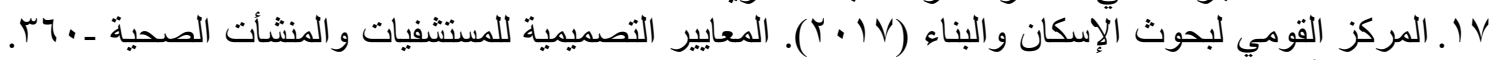
الجزء الأول، القاهرة: دار الكتب الإنب ولبناء المصرية. 